\title{
Forecasting for a Lagrangian aircraft campaign
}

\author{
A. Stohl ${ }^{1}$, O. R. Cooper ${ }^{1}$, R. Damoah ${ }^{2}$, F. C. Fehsenfeld ${ }^{3}$, C. Forster ${ }^{2}$, E.-Y. Hsie ${ }^{3}$, G. Hübler ${ }^{1}$, D. D. Parrish ${ }^{3}$, and \\ M. Trainer $^{3}$ \\ ${ }^{1}$ Cooperative Institute for Research in Environmental Sciences (CIRES), University of Colorado/NOAA Aeronomy \\ Laboratory, Boulder, CO, USA \\ ${ }^{2}$ Department of Ecology, Technical University of Munich, Germany \\ ${ }^{3}$ NOAA Aeronomy Laboratory, 325 Broadway, 80305 Boulder, CO, USA
}

Received: 3 March 2004 - Published in Atmos. Chem. Phys. Discuss.: 6 May 2004

Revised: 2 July 2004 - Accepted: 5 July 2004 - Published: 12 July 2004

\begin{abstract}
A forecast system has been developed in preparation for an upcoming aircraft measurement campaign, where the same air parcels polluted by emissions over North America shall be sampled repeatedly as they leave the continent, during transport over the Atlantic, and upon their arrival over Europe. This paper describes the model system in advance of the campaign, in order to make the flight planners familiar with the novel model output. The aim of a Lagrangian strategy is to infer changes in the chemical composition and aerosol distribution occurring en route by measured upwind/downwind differences. However, guiding aircraft repeatedly into the same polluted air parcels requires careful forecasting, for which no suitable model system exists to date. This paper describes a procedure using both Eulerian-type (i.e. concentration fields) and Lagrangian-type (i.e. trajectories) model output from the Lagrangian particle dispersion model FLEXPART to predict the best opportunities for a Lagrangian experiment. The best opportunities are defined as being highly polluted air parcels which receive little or no emission input after the first measurement, which experience relatively little mixing, and which are reachable by as many aircraft as possible. For validation the system was applied to the period of the NARE 97 campaign where approximately the same air masses were sampled on different flights. Measured upwind/downwind differences in carbon monoxide $(\mathrm{CO})$ and ozone $\left(\mathrm{O}_{3}\right)$ decreased significantly as the threshold values used for accepting cases as Lagrangian were tightened. This proves that the model system can successfully identify Lagrangian opportunities.
\end{abstract}

Correspondence to: A. Stohl

(astohl@al.noaa.gov)

\section{Introduction}

Field campaigns employing research aircraft are indispensable for understanding physical and chemical processes in the atmosphere and for validating atmospheric models. During these campaigns, it is of utmost importance to have available accurate forecasts in order to guide the aircraft into air masses with targeted properties. Until about a decade or so ago, the flight planning was supported only by weather forecasts and trajectory models. Since these models do not give quantitative information about the distribution of trace gases and aerosols, the idea arose in the 1990's of employing chemistry transport models (CTMs) to predict the chemistry and transport of trace substances for the flight planning. The first field campaigns supported by CTM forecasts were, in the stratosphere, ASHOE and SESAME (Lee et al., 1997) which took place in 1994-1995 and, in the troposphere, POLINAT (Flatøy et al., 2000) in 1997. Now all major field campaigns are routinely supported by CTM forecasts (see, e.g. Lawrence et al. (2003); Jacob et al. (2003)). Some of the recently developed forecast systems even assimilate real-time data (e.g. aerosol optical depth) from satellite measurements (Rasch et al., 2001) similar to the assimilation of meteorological data in current weather forecast models. Trajectory models have been further developed, too. For instance, domainfilling trajectory calculations can supply valuable information that is complementary to CTM results (Methven et al., 2003).

During most missions, aircraft are sent into air masses predicted to have certain properties (e.g. high levels of pollution), but without considering other scientific constraints. Sometimes, however, it is desirable to probe the same air mass repeatedly, for instance to investigate how the chemical composition changes with time, how clouds are forming or cloud properties are changing. Such a measurement strategy 
can yield observation-based constraints on, for instance, reaction rates, particle growth rates, or surface fluxes. Despite these promising properties, few Lagrangian campaigns have been performed to date. The ASTEX/MAGE experiment derived air/sea exchange rates from chemical budgets (Huebert et al., 1996), the ACE experiments measured changes in aerosol properties and abundances (Johnson et al., 2000), and during PARFORCE nucleation events were investigated (O'Dowd, 2002) in moving air parcels. For studying the stratospheric ozone layer, ozone changes have been inferred from sounding data along calculated trajectories (Rex et al., 1999), and recently ozone sonde launches indeed have been coordinated using trajectory forecasts in order to maximize the number of Lagrangian "matches". All these experiments were relatively simple, as they took place in either relatively steady boundary-layer outflow (sometimes also on rather small scales) or laminar flows in the stratosphere. None of them was performed under conditions involving significant vertical motions. Due to the relative simplicity of the flow in some campaigns, tetroons could be used for tagging specific air parcels (Businger et al., 1999) which reduced the dependence of the flight planning on meteorological analyses and forecasts.

The situation is very different for dynamically active situations in the troposphere or when convection is present. Under these conditions vertical winds can move air parcels from the boundary layer to the tropopause region within a short time period. Constant level balloons therefore cannot be used to tag air parcels. For instance, intercontinental transport (ICT) of air pollution often involves lifting over or downwind of a source continent, followed by fast transport with the jet stream to the receptor continent (Stohl and Trickl, 1999; Stohl, 2001). Never has a Lagrangian experiment been attempted under such meteorologically complex conditions. However, exactly that was recently proposed and accepted as a task of the International Global Atmospheric Chemistry (IGAC) project (see http://www.igac.noaa.gov). So far, the impact of ICT of air pollution on the atmospheric composition and air quality over a downwind continent is known only from model calculations (Wild et al., 2001; Li et al., 2002) and a few observations (Jaffe et al., 1999; Stohl and Trickl, 1999; Stohl et al., 2003; Nowak et al., 2004) for which the conditions over the upwind continent are normally not well characterized. The new IGAC task could produce much-needed data to constrain global model calculations. Its objective is to determine the photochemical oxidant and aerosol formation potentials in polluted air masses originating in North American emission regions and their chemical evolution as they are transported out over the North Atlantic and towards Europe. Approximately 10 extensively instrumented research aircraft will be deployed on both sides of the Atlantic in summer 2004, giving a good chance for a Lagrangian experiment that aims at sampling the same air masses repeatedly. Its execution, however, is by no means trivial and will require careful flight planning.
To date, no modeling tools are available that are designed specifically for the requirements of a Lagrangian campaign. To demonstrate this point, we take the example already described by Stohl et al. (2003) and analyzed in detail by Huntrieser et al. (2004) ${ }^{1}$. In Fig. 1, total columns of a modeled North American CO tracer are shown for 13 November 2001 at 00:00 UTC and 19 November 2001 at 12:00 UTC. Using the tracer forecasts, a research aircraft was successfully guided into the pollution plume over Europe on 19 November (the white line in Fig. 1 indicates the flight leg). The measurements confirmed the presence of heavily polluted air from North America (Stohl et al., 2003; Huntrieser et al., 2004 ${ }^{1}$ ). The plots shown in Fig. 1 are typical of the model output that is normally available for the flight planning. From a time sequence of the $\mathrm{CO}$ tracer we know that the plume over North America on 13 November was transported across the Atlantic and developed into that seen over Europe on 19 November. However, exactly which part of the plume on 13 November connects in a Lagrangian sense to a particular part of the plume on 19 November remains unknown. No upwind aircraft was available at this time, but if one were present, which part of the plume should it have optimally targeted? Similarly, if an upwind aircraft had sampled the air on 13 November, to where should the downwind aircraft have best been sent, based on forecast products similar to those shown in Fig. 1? Note that the three-dimensional nature of the plume adds an extra dimension to the problem.

The large area occupied by the plume over North America on 13 November suggests that different parts of the plume originated from very different source regions with different emission characteristics. The variability in $\mathrm{CO}$ tracer concentrations within the plume already indicates differences in emission input. Other species emitted from anthropogenic sources would show a slightly different picture, species from biogenic emissions would have an even more widely differing distribution, and the background concentrations in the plume before it received the emissions would also vary. The relatively small changes in the concentrations of some trace species during ICT, which are to be inferred by the differences between the upwind and the downwind data, could therefore easily be overwhelmed by the composition variability inside the plume. Even aircraft with long endurance can obviously not sample the entire volume occupied by the plume seen in Fig. 1. It is therefore of utmost importance for a Lagrangian experiment that the upwind and downwind aircraft sample the same portion of a plume and not just the same plume in general.

\footnotetext{
${ }^{1}$ Huntrieser, H., Heland, J., Schlager, H., Forster, C., Stohl, A., Aufmhoff, H., Arnold, F., Scheel, E., Campana, M., Gilge, S., Eixmann, R., and Cooper, O. R.: Intercontinental air pollution transport from North America to Europe: Experimental evidence from airborne measurements and surface observations, J. Geophys. Res., submitted, 2004.
} 
But without additional information, the chance that the flight planners could guide two or more aircraft into the same air parcel would be very small.

In order to be successful, Lagrangian measurements must meet several requirements: Firstly, of course, they must be made along a Lagrangian trajectory. Secondly, heavily polluted air must be sampled in order to observe strong-enough signals. Thirdly, the targeted air parcel must not receive significant emission input between two Lagrangian measurements. And fourthly, conditions must be avoided where strong mixing occurs. A certain degree of mixing is unavoidable and thus, strictly, two point measurements can never be truly Lagrangian (it may therefore indeed be preferable to speak of pseudo-Lagrangian measurements). Observations show that pollution levels can still be very high over a downwind continent (Nowak et al., 2004), indicating little dilution, but sometimes mixing can be very important, such as in the case observed by Parrish et al. (2000), where polluted air mixed with air of recent stratospheric origin. The latter conditions must be avoided.

Trajectory models and CTMs can predict information about the first and the second of the above four conditions, respectively. Domain-filling trajectories can also inform about likely regions of mixing. However, no existing model provides information on all four of them. Combining a CTM with a trajectory model could be a solution, but would require close coupling between the two models. This paper describes a model system that has been developed strictly around the four criteria mentioned above. In the next section, the model upon which this system has been built is described, and in Sect. 3 its particular setup for identifying quasi-Lagrangian opportunities is explained. In Sect. 4 the model is run for the period of a previous field study. Flight locations that come closest to being Lagrangian are identified and the measurement data obtained at these locations are used to evaluate the success in identifying Lagrangian cases for progressively more stringent match criteria. Finally, in Sect. 5 conclusions are drawn.

\section{Model Description}

The model around which the forecast system has been built is the Lagrangian particle dispersion model FLEXPART (Stohl et al., 1998; Stohl and Thomson, 1999) (see also http://www.forst.tumuenchen.de/EXT/LST/METEO/stohl/), which simulates the transport and dispersion of linear tracers by calculating the trajectories of a multitude of particles. It was applied previously both for case studies (Stohl and Trickl, 1999; Forster et al., 2001; Stohl et al., 2003) and a climatology of ICT (Stohl et al., 2002a), and it also served as a forecast system during aircraft missions targeted towards intercontinental import of pollution over Europe (Stohl et al., 2003) and North America (Forster et al., 2004). Generally, the model

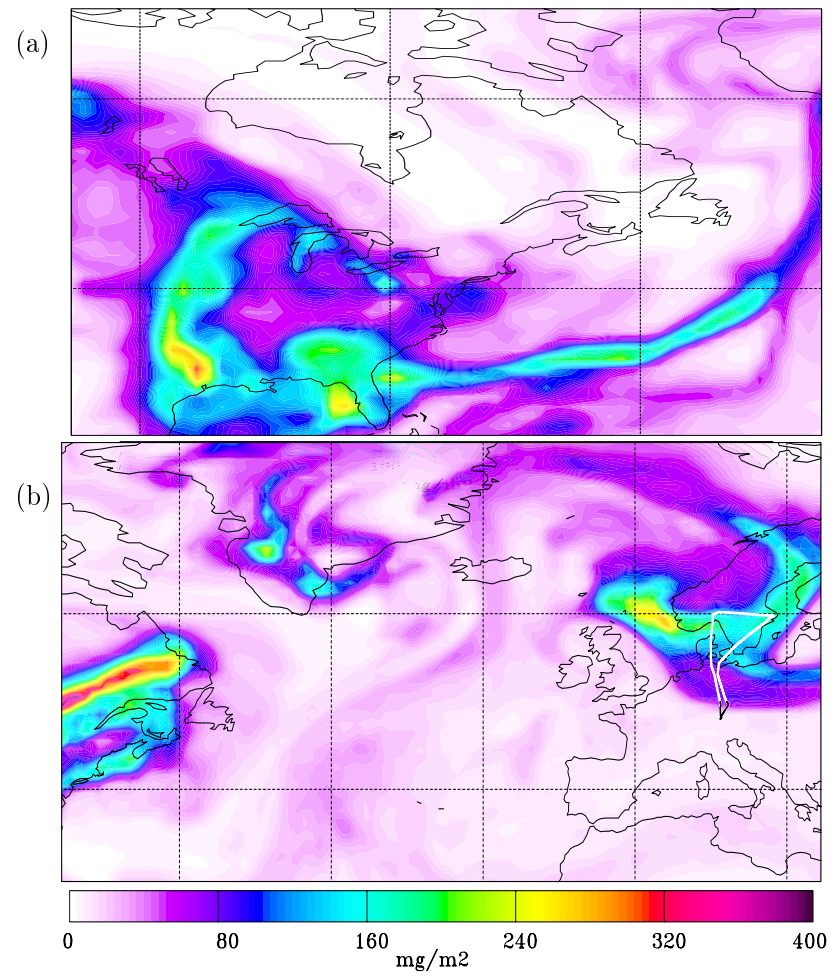

Fig. 1. Total columns of a North American CO tracer on (a) 13 November 2001 at 00:00 UTC and on (b) 19 November 2001 at 12:00 UTC over eastern North America and the North Atlantic region, respectively. The white line in (b) over Central and Northern Europe represents the flight track of the research aircraft guided into the plume.

system predicted the intercontinental transport of pollution plumes quite well (Stohl et al., 2003; Forster et al., 2004). While the plume altitudes and depths were sometimes not accurately predicted, the aircraft could almost always find the predicted layers when vertical profiles were performed.

FLEXPART can be driven by either global model-level data from the European Centre for Medium-Range Weather Forecasts (ECMWF, 2002) or by pressure-level data from the Global Forecast System (GFS) model of the National Center for Environmental Prediction (NCEP). Both data sets have a temporal resolution of $3 \mathrm{~h}$ (analyses at $0,6,12,18 \mathrm{UTC}$; $3 \mathrm{~h}$ forecasts at $3,9,15,21 \mathrm{UTC}$ ) and a horizontal resolution of $1^{\circ} \times 1^{\circ}$. The GFS data are available on 26 pressure levels between $1000 \mathrm{hPa}$ and $10 \mathrm{hPa}$, while the ECMWF data have 60 model (so-called $\eta$ ) levels. The tracer concentrations on a three-dimensional output grid are determined by summing up the mass fractions of all particles located in an output grid cell and dividing them by the grid cell volume. To obtain the mass fraction of each particle and each grid cell in an efficient way a uniform kernel method is used (Stohl et al., 1998). In order to avoid artificial smoothing of concentration fields near the source, the uniform kernel is not used during the first $3 \mathrm{~h}$ after a particle's release. 
Table 1. Summary of the criteria used to predict Lagrangian opportunities.

\begin{tabular}{lr}
\hline Criterion & Threshold value \\
\hline Minimum downwind mixing ratio of the CO tracer for aircraft over the Atlantic and Europe & $50 \mathrm{ppb}$ \\
Minimum downwind mixing ratio of the CO tracer for aircraft over North America & $220 \mathrm{ppb}$ \\
Maximum distance to aircraft base & Depending on aircraft range \\
Maximum CO tracer increase in an air parcel at any time relative to the starting value & $20 \%$ \\
Maximum dispersion of an air parcel & $100 \mathrm{~km}+5 \%$ of travel distance \\
\hline
\end{tabular}

Particles are transported both by the resolved winds and parameterized sub-grid motions. FLEXPART parameterizes turbulence in the boundary layer and in the free troposphere by solving Langevin equations (Stohl and Thomson, 1999). To account for convection, FLEXPART uses a parameterization scheme (Emanuel and Živković-Rothman, 1999; Seibert et al., 2001) which is based on the buoyancy sorting principle. The tracer particles in a convectively active grid cell are randomly displaced in the vertical according to the mass redistribution matrix provided by the convection scheme.

To simulate the transport of North American emissions, a CO tracer is emitted over North America according to the EDGAR version 3.2 inventory (Olivier and Berdowski, 2001) (base year $1995,1^{\circ}$ resolution) ${ }^{2}$. The CO tracer is represented by about 100000 particles released per day according to the emission distribution. Particles are carried over 20 days, after which they are removed from the simulation. A similar model setup was used previously for flight planning (Lawrence et al., 2003; Stohl et al., 2003; Forster et al., 2004).

\section{Identification of Lagrangian opportunities}

The model system is being described as it shall be used in the field to predict Lagrangian opportunities. In the post analysis it can also be used to identify Lagrangian relationships between segments of already performed flights. This is a relatively simple situation because of the limited number of cases - a subset of the much larger number of eventual Lagrangian opportunities that must be considered for flight planning. Even in the field two cases can be distinguished: Firstly, air parcels that have been sampled during previous flights shall be flown into again. Secondly, no flight has yet been performed and all flights are still to be planned. The second case is the more general one and, thus, shall be described first.

Normally, FLEXPART produces 3-hour mean fields of the $\mathrm{CO}$ tracer distribution as shown in Fig. 1, but this is insufficient to identify Lagrangian opportunities. Therefore, particles are numbered and their positions are saved every $3 \mathrm{~h}$,

\footnotetext{
${ }^{2}$ After work on this paper was finished, a new high-resolution emission inventory for North America compiled by S. A. McKeen and G. Frost became available and was implemented in FLEXPART.
}

too. All particle trajectories represent opportunities for a Lagrangian experiment but not all of them are equally good and many are in fact impossible to realize. For instance, for an air parcel traveling out of the range of all participating aircraft, a Lagrangian flight pattern is not feasible. If pollution plumes are to be targeted, less polluted air parcels should be avoided. To identify feasible and meaningful candidates for a Lagrangian experiment, Eulerian (i.e. mixing ratio fields) and Lagrangian (i.e. particle trajectories) information must be combined.

In the first step, all grid cells of the four-dimensional model output (grid cell size $1^{\circ} \times 1^{\circ} \times 1000 \mathrm{~m} \times 3$ hours) outside the range of all participating aircraft (both horizontally and in terms of their maximum ceiling height) are excluded from further analysis. Of the remaining cells, those with a tracer mixing ratio below a certain threshold are also removed. All particles residing in a remaining grid cell (typically a few dozen to a few hundred, depending on the mixing ratio) are then used to tag the grid cell's air, which is hereinafter referred to as an air parcel in order to distinguish it from single particles. The particles of the air parcel are traced back in time, forming what may be called a retroplume (Stohl et al., 2002b). After $24 \mathrm{~h}$ (this minimum time is used to avoid trivial Lagrangian cases such as a second sampling during the same flight), it is checked at every time step whether the air parcel's centroid location can be reached by one of the aircraft. Note that this can also be the same aircraft again, thus performing a Lagrangian experiment on its own. Parcel trajectories are discontinued as they leave the range of the last aircraft that can reach them, and many trajectories are in fact immediately terminated because they never come into (or remain after $24 \mathrm{~h}$ in) the range of an aircraft. Two more criteria must be met: Firstly, the CO tracer mixing ratio of an air parcel must not decrease strongly backward in time because this indicates $\mathrm{CO}$ tracer emission into the air parcel. A small relative decrease is permitted, however, to allow moderate emission input. Secondly, the particles' root-mean-square distance from their centroid must remain below a certain threshold (i.e. effectively, the "volume" occupied by the particles must not grow strongly) because a quickly growing retroplume indicates large opportunities for mixing, which is to be avoided. Note that this effectively also reduces the number of cases where particle trajectories diverge rapidly, which often also indicates that the errors in the simulated transport are large. 
The threshold values of the various criteria used to accept or reject cases as Lagrangian are listed in Table 1. For the aircraft over the North Atlantic and Europe, a North American $\mathrm{CO}$ tracer mixing ratio of $50 \mathrm{ppb}$ was used, because it is typical for the conditions in the center of a moderately polluted North American plume over Europe. Over North America itself, where high $\mathrm{CO}$ tracer mixing ratios are common, a more selective threshold of $220 \mathrm{ppb}$ can be used. The maximum scan radii around the aircraft bases and maximum scan altitudes depend on the aircraft's characteristics and can be chosen differently for every aircraft. Additional emission input was limited rather strictly by a maximum mixing ratio increase of $20 \%$ between the upwind sampling location and any point downwind along the trajectory (i.e. not only the downwind sampling point, where the mixing ratio may have decreased again due to dilution). Dispersion was limited by a root-mean-square distance of the particles to the parcel's centroid of $100 \mathrm{~km}$ plus $5 \%$ of the travel distance. Physically, a constant dispersion threshold would be better, but this leads to the identification of relatively few cases over Europe. Therefore, the criterion was relaxed, depending on the parcel's travel distance.

All these thresholds are subjective and were determined by inspecting daily forecasts over a period of circa four months, while the system was developed, and experimenting with the criteria, such that a visually optimum number of air parcels was identified. The forecasts are made publicly available at the website http://www.al.noaa.gov/metproducts/icartt04/, where the candidates for a Lagrangian experiment are displayed as swarms of small dots superimposed on maps of the total columns of the $\mathrm{CO}$ tracer. Each dot represents the centroid of a selected air parcel. Depending on the meteorological situation thousands of air parcels, many starting from neighboring grid cells in the same plume, are found. Because they do not all represent equally good opportunities for a Lagrangian experiment they are ranked according to their mixing ratio weighted with the number of the aircraft that can possibly sample it. The plotting is done such that the best cases are drawn last and are, thus, emphasized. The trajectories of the 50 best cases are furthermore drawn as black lines along which the air parcels (i.e. the dots) move, and for the five best cases larger dots, surrounded by a white ring, are used. A text file lists the centroid trajectories of the ranked air parcels whose exact positions can be used for the final flight planning.

Figure 2 shows a predicted ICT event that is well suited for demonstration. Despite the relative simplicity of this event, the classification of Lagrangian opportunities can fully be comprehended only in a movie of which Fig. 2 presents a few snapshots. For the 5-day Lagrangian forecasts, GFS data were used and it was assumed that three aircraft were stationed at the North American east coast, at the Azores and in Northern France, respectively (the orange dots in Fig. 2). It was furthermore assumed that the three aircraft all had an operating range of $1500 \mathrm{~km}$ (the orange circles in Fig. 2) and maximum ceiling altitudes of 8,10 and $11 \mathrm{~km}$. On 28 January 2004 there was a quasi-stationary low-pressure system centered over Newfoundland. On its southern end it spawned another cyclone on 29 January that over the next few days travelled towards Iceland. South of the two cyclones a strong zonal flow was established that at low levels channelled air pollution from North America to Europe. At the start of the Lagrangian forecast (Fig. 2a) at 09:00 UTC on 28 January 2004 (which is already 3 hours into the meteorological forecast), three parcel swarms are identified as Lagrangian opportunities: a small one southwest of the Azores, and two other ones over eastern North America, respectively. Note that at the start and at the end of a forecast, air parcels are present only within the range of one of the aircraft because every trajectory must start and end at possible sampling points. The air parcels southwest of the Azores tag CO tracer from a previous continental outflow event, while the two swarms of air parcels over North America tag relatively fresh pollution that is just about to leave the continent. Note that there is a region with very high total $\mathrm{CO}$ tracer columns connecting the two parcel swarms where no Lagrangian opportunities were found suitable. This is a region where subsequently very strong dispersion occurs while the polluted air mass is split into two parts. The southeastern parcel swarm leaves North America directly in the strong zonal flow, while the northwestern swarm is at first blocked by the cyclone. Air parcels in between (not shown here) are scattered over much of the Atlantic Ocean over the next few days. Therefore, this part of the pollution plume, while eventually also transported to Europe, is not a suitable candidate for a Lagrangian experiment. The 50 best opportunities have all been identified in the southeastern part of the plume from where trajectories plotted as black lines - emanate. Note that the CO tracer mixing ratio in the parcel classified as the best opportunity is about $180 \mathrm{ppb}$.

On 30 January at 00:00 UTC (Fig. 2b), the two swarms originating over North America 27 hours before are now clearly separated, with the leading one entering the range of the Azores-based aircraft. A few new parcels have now been identified also in between the two main swarms and new parcels are also added at the North American aircraft's western boundary as polluted air is swept into its range. Two isolated parcels have also been identified over Europe (one is located between Ireland and England) in streams of pollution arriving from the northwest. These parcels can only be sampled by the European aircraft performing a Lagrangian experiment on its own.

On 31 January at 06:00 UTC (Fig. 2c) the major swarm of air parcels has become horse shoe shaped, as its leading part becomes sucked into the downwind cyclone's warm conveyor belt. These parcels west of Ireland now travel at about $7-8 \mathrm{~km}$ altitude, whereas the main stream of parcels further south is still located at $1 \mathrm{~km}$. The second main swarm has now also left North America and encroaches on the Azores. The swarm originally over the Azores on 28 January has 
a) 28 January 9 UTC

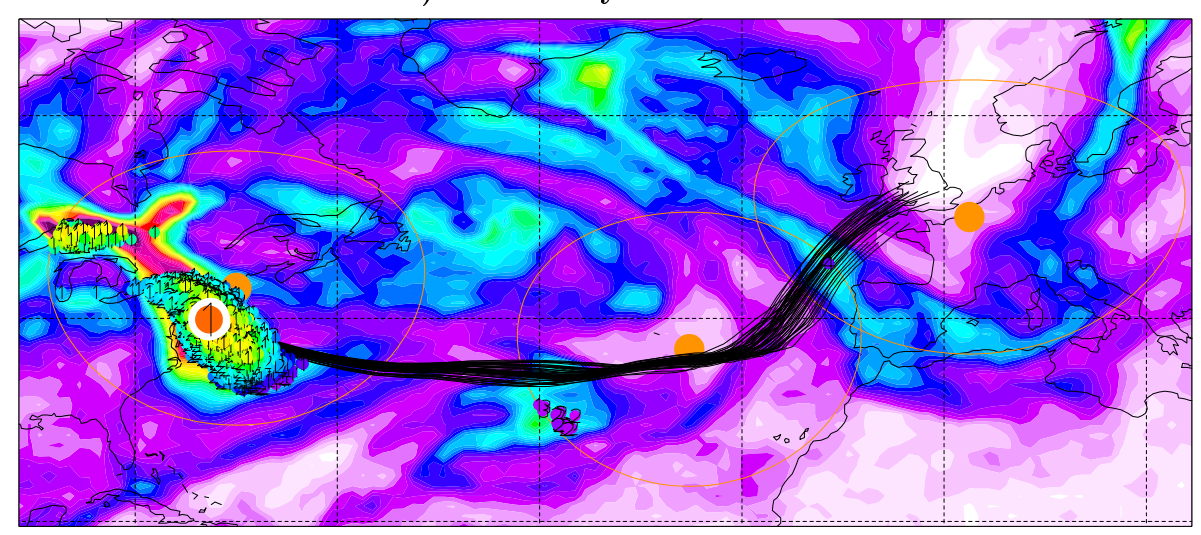

b) 30 January 0 UTC
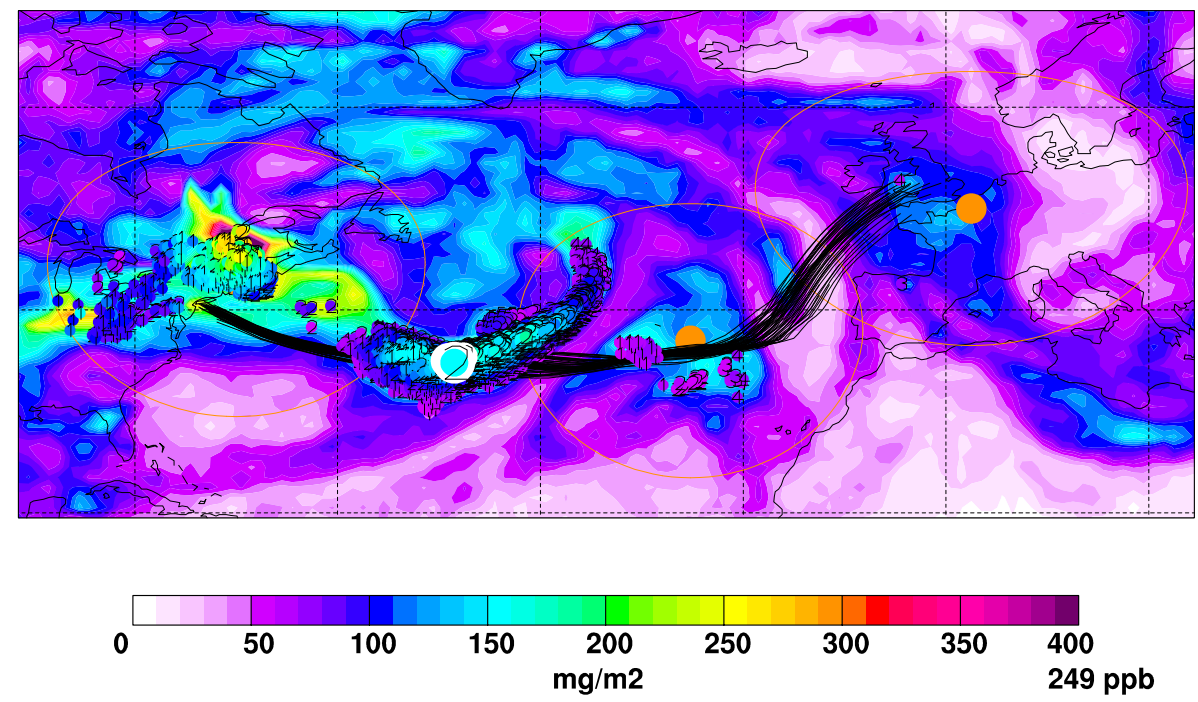

Fig. 2. Example for a 5-day Lagrangian forecast assuming no flight has yet been performed. The forecast maps from top to bottom are for (a) 28 January 2004 at 09:00 UTC (3 h after the forecast start), (b) 30 January 2004 at 00:00 UTC, (c) 31 January 2004 at 06:00 UTC, (d) 1 February 2004 at 06:00 UTC, and (e) 2 February 2004 at 06:00 UTC. Orange dots show the assumed bases of three aircraft and orange circles indicate their ranges of operation. The centroid locations of air parcels selected as Lagrangian opportunities are presented as dots superimposed on maps of the total North America CO tracer columns. The dots are colored according to the actual CO tracer mixing ratio in the air parcel using the same color scale as used for the total columns, but scaled to a maximum value of 249 ppb. Note, therefore, that the colors of the dots do not match with the colors of the background contours, which show total columns rather than mixing ratios. The number drawn on top of each dot indicates the air parcel's centroid altitude in kilometers. The five best Lagrangian opportunities are drawn as bigger circles surrounded by a white ring (only three are visible which cover the other two). The trajectories of the 50 best cases are also shown as black lines.

dispersed: some of the parcels are still close to the Azores, others have entered into the range of the European aircraft, while still others have travelled out of the reach of all aircraft and have disappeared from the plots.

24 hours later, on 1 February at 06:00 UTC (Fig. 2d) the warm conveyor belt parcels have separated from the main part of the plume and are already located east of the European aircraft's base, while the main filament is slowly entering the European domain from the southwest. Meanwhile, the second swarm of particles has entered a faster zonal flow north of the first swarm and is starting to overtake it. Very few new Lagrangian opportunities are identified in the relatively clean air left over North America after the outflow event. The moderate maxima seen there in the total CO columns are in the process of being generated by fresh emissions, which per definition prevents a Lagrangian experiment. Other regions are too clean to classify for a Lagrangian experiment. This is very typical for the situation after a major pollution outflow event.

On 2 February at 06:00 UTC (Fig. 2e), $12 \mathrm{~h}$ before the end of the forecast, the parcels being classified as providing the best Lagrangian opportunities have arrived in the range of the 
c) 31 January 6 UTC

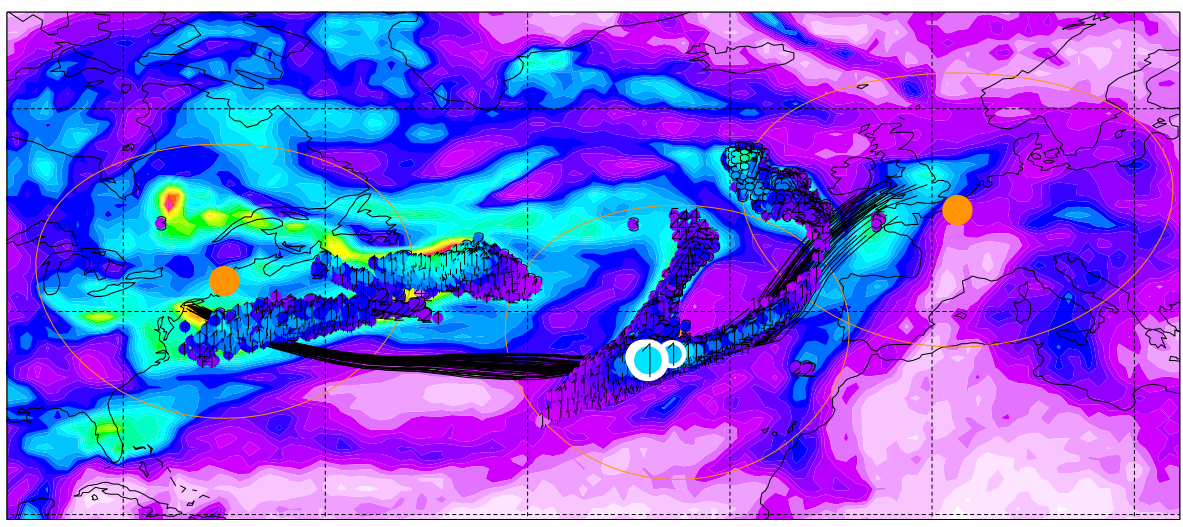

d) 1 February 6 UTC

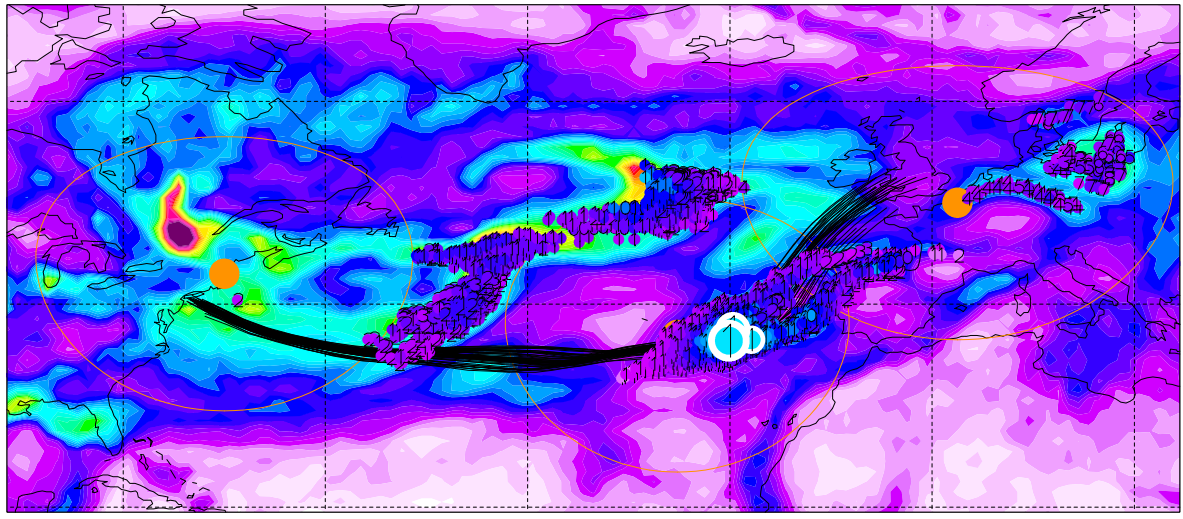

e) 2 February 6 UTC
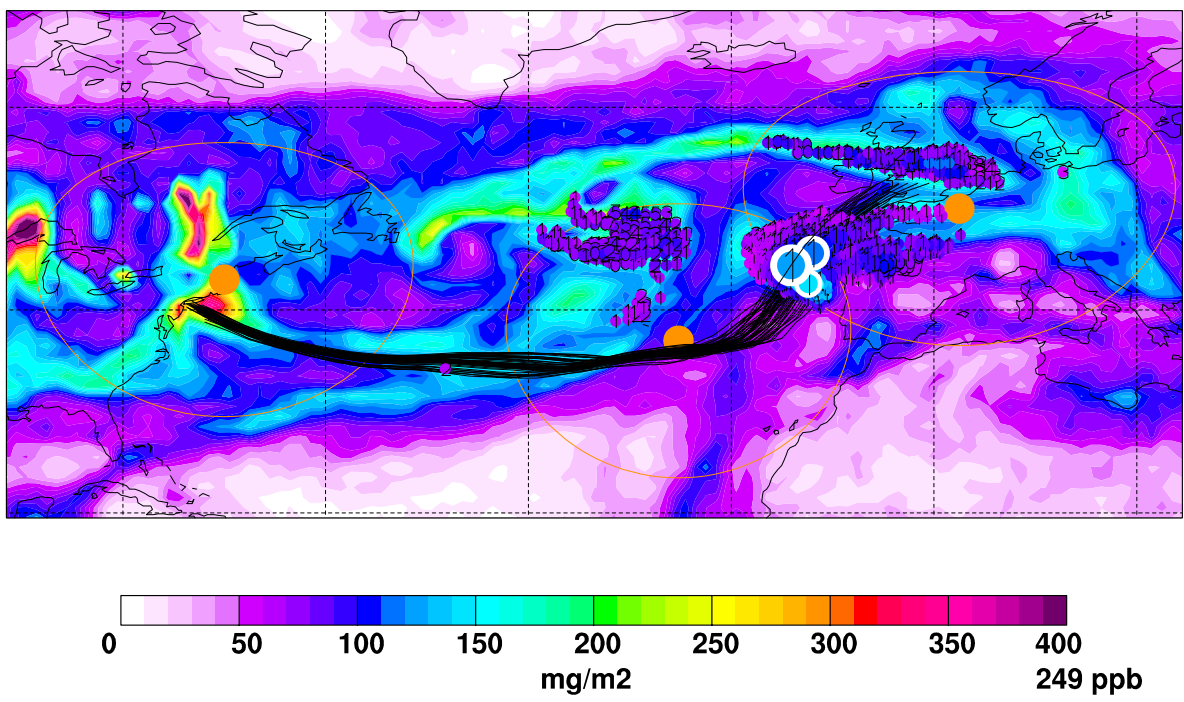

Fig. 2. Continued.

European aircraft and accelerate towards southern England. Note that even in these parcels, the $\mathrm{CO}$ tracer mixing ratio has dropped from originally $180 \mathrm{ppb}$ to $60-100 \mathrm{ppb}$. It is likely, though, that an aircraft could still sample relatively undiluted air preserved in filaments that are not captured in our simulation. Located in a stream from west of Ireland to northern Germany is a particle swarm that originated from the second pollution pocket and which has now overtaken the trailing parcels of the first swarm. Another part of the second swarm is located over the Azores. The mixing ratios in both 
parts of the second swarm are about 40-80 ppb, not much lower than in the first swarm. However, the opportunities for the second swarm were ranked lower because only two aircraft could have sampled it.

In summary, the optimum Lagrangian experiment for this outflow event would have applied the following measurement strategy. Firstly, the North American airplane would have sampled the first particle swarm on 28 and/or on 29 January. Secondly, the plane based on the Azores would have sampled on one or two of the days from 30 January to 2 February. Thirdly, the European aircraft could have sampled from 2 February.

At least in movies the source receptor relationships of this ICT event become quite clear using the novel technique, and clear guidance is provided on the best Lagrangian sampling strategy. With the Eulerian-type tracer information alone the complex tracer distribution over Europe could not have been traced back to the particular source regions over North America, and upwind and downwind aircraft very likely would have sampled different parts of the plume. The North American aircraft could have also been sent into that part of the plume that later became strongly dispersed. This example was chosen for its simplicity due to the flow being largely two-dimensional. In other cases, when the threedimensional source receptor relationships are more complex, the new forecast product is even more necessary. Note that while the example described above would have given each aircraft sampling opportunities for longer than a day, there are also cases where the window of opportunity is much shorter. Sometimes an opportunity may arise only during the nighttime, which requires high flexibility of the personnel involved.

In the simpler case when one or more flights have already been performed and opportunities for re-sampling the same air shall be identified, the same procedure as above is used. However, instead of starting air parcels from the cells of the output grid, they are started from boxes of size $0.7^{\circ} \times 0.7^{\circ} \times 400 \mathrm{~m}$ centered along the flight track. These parcels are then traced forward in time. Otherwise the procedure is the same as described above. If measurement data (e.g. CO mixing ratios) from the existing flights are available in real time, measured data rather than the model data can optionally be used to assign priority for following air parcels. In the forecast plots, additional colored circles around the moving dots indicate the measured mixing ratios. Examples for forward projections of already (so far, hypothetically) sampled air parcels can be seen on the forecast webpage.

\section{Validation}

Validation of the Lagrangian forecast system is difficult because to date no Lagrangian flights have been performed intentionally based on accurate forecasts. Partly we must rely on existing validation studies of the underlying FLEXPART model (Stohl et al., 1998, 2003; Forster et al., 2004). During the North Atlantic Regional Experiment in September 1997 (NARE 97), however, 13 flights were performed from St. John's, Newfoundland, Canada. The flights covered the western and central North Atlantic Ocean and sampled a variety of meteorological conditions that led to transport of air from the boundary layer to the free troposphere, the continental to marine troposphere, and the stratosphere to the troposphere. Because of the relative spatio-temporal density of the flight data during NARE 97, there is a good chance that some flight segments connect at least approximately to some others in a Lagrangian sense. Furthermore, it was already tried to realize Lagrangian flights as part of the experiment. Whether these plans were successful or not, however, was never analyzed. An overview of NARE can be found in issue 24 (August 2001) of the IGACtivities Newsletter, and publications describing the general flight patterns and some of the data obtained during NARE 97 are Cooper et al. (2001) and Stohl et al. (2002c).

As no meteorological forecast data were available for the NARE 97 period, data from the recent ECMWF 40-year reanalysis project (Simmons and Gibson, 2000) were used instead. While the performance of the model system is likely to be superior with analysis than with forecast data, it is our experience that tracer forecasts are not highly sensitive to the forecast period up to about two or three days and are normally quite similar to tracer analyses (Lawrence et al., 2003). For the purpose of testing the particular model setup for the Lagrangian experiment, the re-analysis data are therefore deemed adequate.

Using our model system we identified Lagrangian cases between the NARE flights and investigated the measured upwind/downwind differences of two reasonably long-lived chemical tracers, $\mathrm{CO}$ and $\mathrm{O}_{3}$. Both species have lifetimes of the order of about a month or longer (Seinfeld and Pandis, 1998; Liu et al., 1987) and chemical changes are therefore expected to be relatively small over the course of a few days. $\mathrm{CO}$ can be produced by the oxidation of hydrocarbons and destroyed by $\mathrm{OH}$ oxidation. $\mathrm{O}_{3}$ may also be photochemically produced or destroyed. Most Lagrangian cases were identified between flights two or three days apart, for which chemical changes of both species should be no more than about $10 \mathrm{ppb}$, with the exception of $\mathrm{O}_{3}$ formation in strongly polluted air masses.

We traced air parcels 8 days forward from all 1-minute average flight positions as described above, but at first without dropping any from the analysis. Then we applied combinations of some criteria discussed above to exclude cases. As the downwind aircraft never exactly intercepted a previously sampled air parcel advected from an upwind flight, we also must define how closely the air parcel's centroid position and the downwind aircraft's position must match for accepting the case as Lagrangian.

Figure 3 shows the mean absolute difference between the upwind and downwind $\mathrm{CO}$ measurements in dependence of 


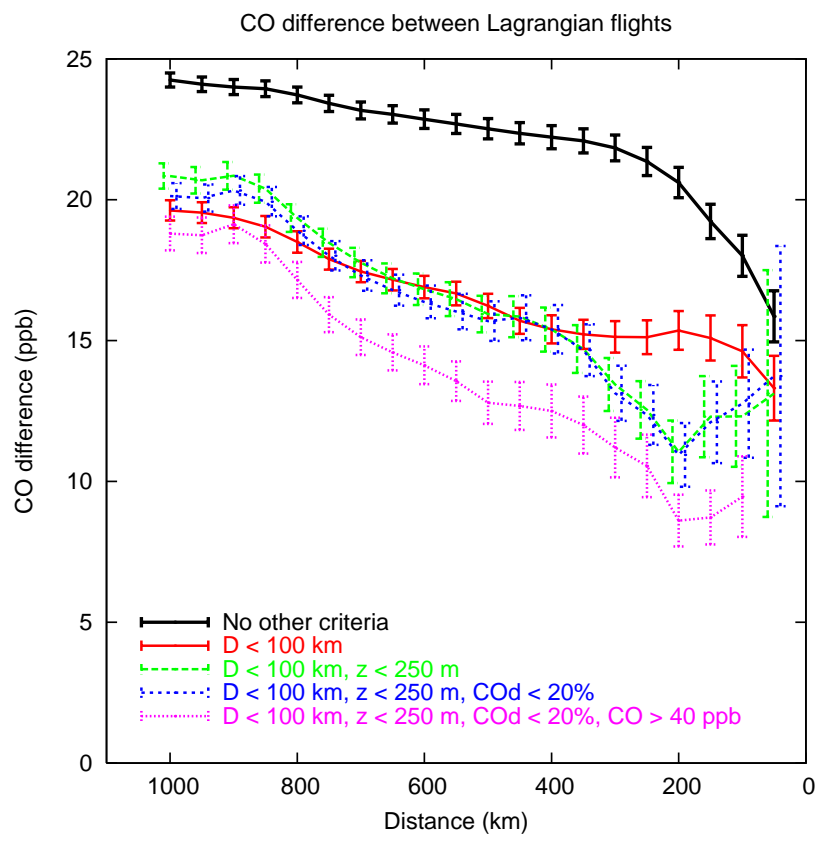

Fig. 3. Average absolute difference between upwind and downwind measurements of $\mathrm{CO}$ and its dependence on the maximum allowed distance between the forward projected air parcel's centroid location and the position of the downwind aircraft. The black line is for all cases without other restrictions, the red line is when dispersion of the air parcel is limited to a root mean square distance of $100 \mathrm{~km}$, the green line is when, in addition, the two positions must match vertically within $250 \mathrm{~m}$, the blue line is when it is furthermore required that the $\mathrm{CO}$ tracer increase along an air parcel's trajectory must be less than $20 \%$, and the purple line is when in addition the $\mathrm{CO}$ tracer at the downwind location must be larger than $40 \mathrm{ppb}$. Error bars are standard deviations of the means, calculated by assuming that the upwind aircraft's data are independent from each other (i.e. every 1-minute average value counts as an independent case), whereas multiple matches of the same parcel with different downwind data are counted only once. Error bars for the yellow and blue lines are offset by $\pm 10 \mathrm{~km}$ for clarity.

the maximum distance permitted between the air parcel projected forward to the time of the downwind measurement, and the downwind aircraft. If no other criteria are employed (black line), $\mathrm{CO}$ differences decrease from an average of about $25 \mathrm{ppb}$ to $16 \mathrm{ppb}$ as the maximum allowed matching distance decreases from 1000 to $50 \mathrm{~km}$. A reduction in $\mathrm{CO}$ differences to 20 to $13 \mathrm{ppv}$ (depending on matching distance) is achieved if horizontal dispersion of the forward plume is limited to $100 \mathrm{~km}$ (red line), thereby reducing the effects of transport errors and mixing. If in addition positions must match vertically within $250 \mathrm{~m}$ (green line), CO differences are not reduced any more for large horizontal distances, but they drop significantly for horizontal distances less than about $300 \mathrm{~km}$. For the smallest horizontal distances, the number of accepted cases is rather small: 51 for $100 \mathrm{~km}$ and only 14 for $50 \mathrm{~km}$. Therefore, the increase at distances below $200 \mathrm{~km}$ must be considered as noise. Limiting the

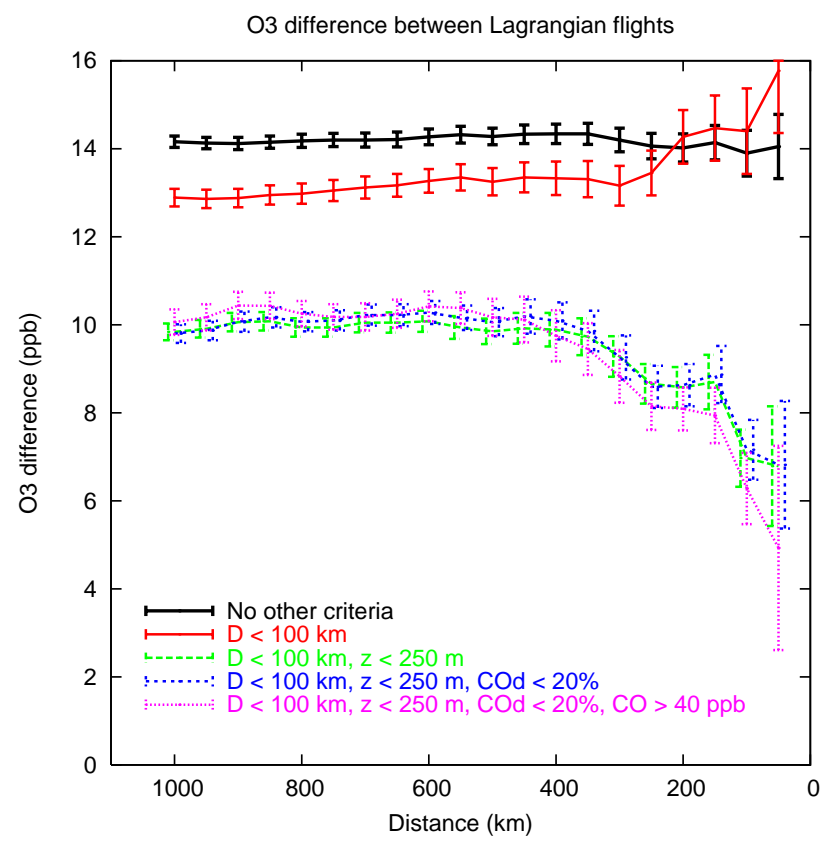

Fig. 4. Same as Fig. 3, but for ozone.

CO tracer increase and thus emission uptake by $20 \%$ (blue line), another small reduction in measured $\mathrm{CO}$ difference is achieved over the entire range of distances tested, with the smallest difference at $200 \mathrm{~km}$ being only $11 \mathrm{ppb}$. This is already what may result from chemical processes over a period of 2 to 5 days. If, in addition, only cases in rather heavily polluted air are considered (minimum $\mathrm{CO}$ tracer mixing ratio of $40 \mathrm{ppb}$ at the downwind location; this differs from our standard criteria shown in Table 1, because of the relatively clean conditions encountered during NARE 97), the CO differences at 150-200 $\mathrm{km}$ are below $8 \mathrm{ppb}$ (purple line). A likely reason for this further reduction is that the centers of pollution plumes by their very nature are not so close to air mass boundaries, where particles diverge rapidly (Cohen and Kreitzberg, 1997), where mixing is strong, and where errors in the simulated transport are likely largest.

Figure 3 shows that all our criteria together succeed in selecting cases where measured differences between upwind and downwind $\mathrm{CO}$ are relatively small. For a horizontal matching distance of $200 \mathrm{~km}$ and applying all other criteria, 65 cases from six different flight combinations ( 6 and 8,8 and 11, 6 and 11, 11 and 13, 8 and 13, and 16 and 18 September, respectively) remain. The 65 cases are not truly independent, because most of the combinations occurred between "neighboring" 1-minute average positions of two matching flights. Even more so, the same upwind data point could match with several downwind points. If these cases are counted only once, then the number of matches is actually only 20 (this is how error bars in Fig. 3 were calculated). This small number shows the limitations of the NARE 97 dataset for verifying the forecast system. 


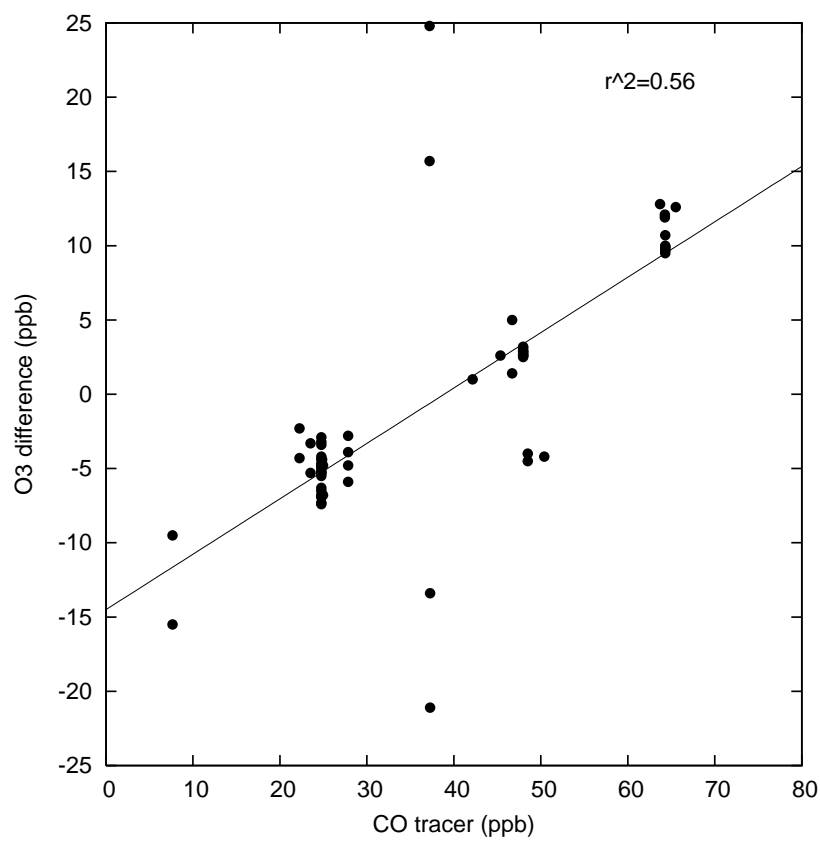

Fig. 5. Dependence of downwind minus upwind ozone mixing ratio on the downwind $\mathrm{CO}$ tracer mixing ratio for Lagrangian matches.

Note that Fig. 3 gives no clear indication which criteria are most effective. It appears, for instance, that excluding cases with a CO tracer increase of more than $20 \%$ (i.e. the limit on the emission input) is not very effective because it decreases the measured $\mathrm{CO}$ difference by less than $1 \mathrm{ppb}$ for most horizontal matches. However, this is due to the sequence with which the different criteria were introduced here. It seems it is the combination of the different criteria, arbitrary as the particular threshold values might be, that selects the best Lagrangian cases.

Figure 4 shows the measured mean absolute upwind/downwind differences for $\mathrm{O}_{3}$ in dependence of the various criteria. In contrast to $\mathrm{CO}, \mathrm{O}_{3}$ differences - about $14 \mathrm{ppb}$ - do not decrease when the horizontal match criterion is made more stringent (black line). The dispersion criterion is not very effective either (red line). However, there is a dramatic decrease if furthermore the vertical distance is limited to $250 \mathrm{~m}$ (green line). Importantly, in combination with the $250 \mathrm{~m}$ vertical match criterion, also the horizontal criterion becomes effective, with $\mathrm{O}_{3}$ differences of less than $9 \mathrm{ppb}$ for about $200 \mathrm{~km}$ and about $7 \mathrm{ppb}$ for $100 \mathrm{~km}$. The likely reason for the relatively greater importance of the vertical match criterion for $\mathrm{O}_{3}$ than for $\mathrm{CO}$ is the stronger vertical gradient in the $\mathrm{O}_{3}$ distribution. Limiting the $\mathrm{CO}$ tracer emission input (blue line) does not reduce the $\mathrm{O}_{3}$ differences further. Selecting strongly polluted cases (purple line) leads to moderate reductions in the $\mathrm{O}_{3}$ differences, but also only for rather accurate horizontal matches. Altogether, the criteria yield $\mathrm{O}_{3}$ differences that are only about 5-7 ppb. As for $\mathrm{CO}$, this is in a range where chemical processes cannot be neglected. In fact, for the very best Lagrangian cases (all above criteria, except for the selection for strongly polluted cases, and with a $75 \mathrm{~km}$ horizontal matching criterion) we find a systematic relationship between downwind minus upwind $\mathrm{O}_{3}$ and the $\mathrm{CO}$ tracer mixing ratio at the downwind location (Fig. 5). Relatively clean cases tend to be associated with $\mathrm{O}_{3}$ destruction, whereas the more polluted cases are associated with $\mathrm{O}_{3}$ formation. All these cases were between flights separated by two or three days, resulting in reasonable chemical $\mathrm{O}_{3}$ destruction or formation rates of the order of a few ppb per day.

Another tracer measured during NARE 97 was total reactive nitrogen $\left(\mathrm{NO}_{\mathrm{y}}\right) . \mathrm{NO}_{\mathrm{y}}$ is removed from the atmosphere by wet and dry deposition, and $\mathrm{NO}_{\mathrm{y}}$ removal was indeed very efficient during NARE 97 (Stohl et al., 2002c). Mean values of the absolute upwind/downwind differences in $\mathrm{NO}_{\mathrm{y}}$ were about $900 \mathrm{ppt}$ for a $1000 \mathrm{~km}$ matching distance with no other criteria applied. Applying all other criteria and a horizontal matching distance of $200 \mathrm{~km}$, mean absolute upwind/downwind $\mathrm{NO}_{\mathrm{y}}$ differences were less than $400 \mathrm{ppt}$. Downwind minus upwind $\mathrm{NO}_{\mathrm{y}}$ concentrations were almost all negative; on average, downwind values were less than $50 \%$ of the upwind values.

Equivalent potential temperature and water vapor mixing ratio measured by the aircraft can also be used as tracers. For instance, with a $250 \mathrm{~m}$ vertical limit, upwind/downwind equivalent potential temperature differences decreased from about $8 \mathrm{~K}$ to $5 \mathrm{~K}$ when the horizontal criterion was lowered from $1000 \mathrm{~km}$ to $200 \mathrm{~km}$. However, this was true only for air parcels remaining at altitudes above $2 \mathrm{~km}$ all the time, thus limiting the available data set considerably. Due to surface fluxes of sensible heat and water vapor these quantities were poorly conserved at lower altitudes, regardless of which matching criteria were used.

\section{Summary and conclusions}

This paper described a forecasting system that has been developed for the purpose of predicting the best opportunities for repeatedly probing the same polluted air masses in a Lagrangian experiment involving several research aircraft. The model system uses a combination of tracer concentration fields and particle trajectories which are both produced self-consistently by the Lagrangian particle dispersion model FLEXPART. The best Lagrangian opportunities are found by identifying grid boxes that are within the range of operation of one of the participating aircraft and which have tracer mixing ratios higher than a preset threshold. The particles inside these grid boxes are then traced backward in time and if they come into the range of another aircraft (or remain sufficiently long within the range of the first aircraft) a Lagrangian measurement is possible. If an air parcel receives fresh emission input, or if it disperses too quickly, the case is disregarded, however. The remaining air parcels are then 
ranked according to their tracer mixing ratio weighted by the number of aircraft that can possibly sample them. They are then displayed on forecast maps as swarms of dots that each are representing a Lagrangian measurement opportunity. If a flight has been performed already, air parcels along the flight track are projected forward using the same method, to predict additional sampling opportunities.

The system was applied to data from the NARE 97 campaign and it was found that measured upwind/downwind differences of $\mathrm{CO}$ and $\mathrm{O}_{3}$ were of the order of about $8 \mathrm{ppb}$ and $6 \mathrm{ppb}$, respectively, for the best identified Lagrangian matches between flights 2 to 5 days apart. These differences are of a magnitude where chemical destruction or production is probably more important than position mismatches, an important requirement for a successful chemical analysis of Lagrangian data.

While we are confident that the new system will predict Lagrangian opportunities reasonably well, there are also limitations. We know, for instance, from previous campaigns (Stohl et al., 2003; Forster et al., 2004) that pollution plume altitudes are sometimes not accurately predicted over a downwind continent. Therefore, it will be important that the downwind aircraft perform vertical profiles at the locations of predicted opportunities and also characterize the horizontal variability of the chemical composition. Similarly, also the upwind aircraft must sample the variability of the chemical composition in the vicinity of a predicted opportunity in order to enhance the chances for a match. As no model, not even in retrospective simulations, is accurate enough to confirm a Lagrangian situation, it will finally be the measurement data that will allow to verify whether a predicted situation was truly Lagrangian, or not.

Five-day forecasts with the new forecast system are now provided operationally on the website http://www.al.noaa. gov/metproducts/icartt04/. It is planned to use this forecast system in the upcoming multi-agency field campaign in summer 2004 (see http://www.al.noaa.gov/ICARTT/) for coordinating the deployment of several research aircraft in North America, the Azores, and Europe. This paper described the system in advance of this campaign in order to make flight planners familiar with the rather unusual product.

Acknowledgements. ECMWF and the German Weather Service are acknowledged for permitting access to the ECMWF re-analysis data, and NCEP for providing the GFS forecast data. We thank all people making the NARE 97 campaign a success, and are grateful for the many comments we have received during the last few months while the system was tested operationally.

Edited by: J. Brandt

\section{References}

Businger, S., Johnson, R., Katzfey, J., Siems, S., and Wang, O.: Smart tetroons for Lagrangian air-mass tracking during ACE 1, J. Geophys. Res., 104, 11 709-11 722, 1999.

Cohen, R. A. and Kreitzberg, C. W.: Airstream boundaries in numerical weather simulations, Mon. Wea. Rev., 125, 168-183, 1997.

Cooper, O. R., Moody, J. L., Parrish, D. D., Trainer, M., Ryerson, T. B., Holloway, J. S., Hübler, G., Fehsenfeld, F. C., Oltmans, S. J., and Evans, M. J.: Trace gas signatures of the airstreams within North Atlantic cyclones: Case studies from the North Atlantic Regional Experiment (NARE '97) aircraft intensive, J. Geophys. Res., 106, 5437-5456, 2001.

ECMWF: IFS Documentation, edited by White, P. W., ECMWF, Reading, UK, 2002.

Emanuel, K. A. and Živković-Rothman, M.: Development and evaluation of a convection scheme for use in climate models, J. Atmos. Sci., 56, 1766-1782, 1999.

Flatøy, F., Hov, O., and Schlager, H.: Chemical forecasts used for measurement flight planning during POLINAT 2, Geophys. Res. Lett., 27, 951-954, 2000.

Forster, C., Wandinger, U., Wotawa, G., James, P., Mattis, I., Althausen, D., Simmonds, P., O’Doherty, S., Jennings, S. G., Kleefeld, C., Schneider, J., Trickl, T., Kreipl, S., Jäger, H., and Stohl, A.: Transport of boreal forest fire emissions from Canada to Europe, J. Geophys. Res., 106, 22 887-22 906, 2001.

Forster, C., Cooper, O., Stohl, A., Eckhardt, S., James, P., Dunlea, E., Nicks Jr., D. K., Holloway, J. S., Hübler, G., Parrish, D. D., Ryerson, T. B., and Trainer, M.: Lagrangian transport model forecasts and a transport climatology for the Intercontinental Transport and Chemical Transformation 2002 (ITCT 2k2) measurement campaign, J. Geophys. Res., 109, D07S92, doi:10.1029/2003JD003589, 2004.

Huebert, B. J., Pszenny, A., and Blomquist, B.: The ASTEX/MAGE experiment, J. Geophys. Res., 101, 4319-4329, 1996.

Jacob, D., Crawford, J. H., Kleb, M. M., Connors, V. S., Bendura, R. J., Raper, J. L., Sachse, G. W., Gille, J. C., Emmons, L., and Heald, C. L.: Transport and Chemical Evolution over the Pacific (TRACE-P) aircraft mission: Design, execution, and first results, J. Geophys. Res., 108, 9000, doi:10.1029/2002JD003276, 2003.

Jaffe, D., Anderson, T., Covert, D., Kotchenruther, R., Trost, B., Danielson, J., Simpson, W., Berntsen, T., Karlsdottir, S., Blake, D., Harris, J., Carmichael, G., and Uno, I.: Transport of Asian air pollution to North America, Geophys. Res. Lett., 26, 711714, 1999.

Johnson, D. W., Osborne, S., Wood, R., Suhre, K., Johnson, R., Businger, S., et al.: An overview of the Lagrangian experiments undertaken during the North Atlantic regional Aerosol Characterization Experiment (ACE-2), Tellus, 52B, 290-320, 2000.

Lawrence, M. G., Rasch, P. J., von Kuhlmann, R., Williams, J., Fischer, H., de Reus, M., Lelieveld, J., Crutzen, P. J., Schultz, M., Stier, P., Huntrieser, H., Heland, J., Stohl, A., Forster, C., Elbern, H., Jakobs, H., and Dickerson, R. R.: Global chemical weather forecasts for field campaign planning: predictions and observations of large-scale features during MINOS, CONTRACE and INDOEX, Atmos. Chem. Phys., 3, 267-289, 2003.

Lee, A. M., Carver, G. D., Chipperfield, M. P., and Pyle, J. A.: Three-dimensional chemical weather forecasting: A Methodol- 
ogy, J. Geophys. Res., 102, 3905-3919, 1997.

Li, Q., Jacob, D. J., Bey, I., Palmer, P. I., Duncan, B. N., Field, B. D., Martin, R. V., Fiore, A. M., Yantosca, R. M., Parrish, D. D., Simmonds, P. G., and Oltmans, S. J.: Transatlantic transport of pollution and its effects on surface ozone in Europe and North America, J. Geophys. Res., 107, 10.1029/2001JD001422, 2002.

Liu, S. C., Trainer, M., Fehsenfeld, F. C., Parrish, D. D., Williams, E. J., Fahey, D. W., Hubler, G., and Murphy, P. C.: Ozone production in the rural troposphere and the implications for regional and global ozone distributions, J. Geophys. Res., 92, 4191-4207, 1987.

Methven, J., Arnold, S. R., O’Connor, F. M., Barjat, H., Dewey, K., Kent, J., and Brough, N.: Estimating photochemically produced ozone throughout a domain using flight data and a Lagrangian model, J. Geophys. Res., 108, 4271, doi:10.1029/2002JD002955, 2003.

Nowak, J. B., Parrish, D. D., Neuman, J. A., Holloway, J. S., Cooper, O. R., Trainer, M., Ryerson, T. B., Nicks Jr., D. K., Flocke, F., Roberts, J. M., Atlas, E., de Gouw, J. A., Donnelly, S., Dunlea, E., Hübler, G., Huey, L. G., Schauffler, S., Tanner, D. J., Warneke, C., and Fehsenfeld, F. C.: Gas-phase chemical characteristics of Asian emission plumes observed during ITCT $2 \mathrm{k} 2$ over the eastern North Pacific Ocean, J. Geophys. Res., in press, 2004.

O'Dowd, C. D.: On the spatial extent and evolution of coastal aerosol plumes, J. Geophys. Res., 107, 8105, doi:10.1029/2001JD000422, 2002.

Olivier, J. G. J. and Berdowski, J. J. M.: Global emissions sources and sinks, in: The Climate System, edited by Berdowski, J., Guicherit, R., and Heij, B. J., pp. 33-78, A. A. Balkema Publishers/Swets and Zeitlinger Publishers, Lisse, The Netherlands, ISBN 905809255 0, 2001.

Parrish, D. D., Holloway, J. S., Jakoubek, R., Trainer, M., Ryerson, T. B., Hübler, G., Fehsenfeld, F. C., Moody, J. L., and Cooper, O. R.: Mixing of anthropogenic pollution with stratospheric ozone: A case study from the North Atlantic wintertime troposphere, J. Geophys. Res., 105, 24 363-24 374, 2000.

Rasch, P. J., Collins, W. D., and Eaton, B. E.: Understanding the Indian Ocean Experiment (INDOEX) aerosol distributions with an aerosol assimilation, J. Geophys. Res., 106, 7337-7355, 2001.

Rex, M., von der Gathen P., Braathen, G. O., Harris, N. R. P., Reimer, E., et al.: Chemical ozone loss in the Arctic winter 1994/95 as determined by the Match technique, J. Atmos. Chem., 32, 35-59, 1999.
Seibert, P., Krüger, B., and Frank, A.: Parametrisation of convective mixing in a Lagrangian particle dispersion model, Proceedings of the 5th GLOREAM Workshop, Wengen, Switzerland, 24-26 September, 2001.

Seinfeld, J. H. and Pandis, S. N.: Atmospheric Chemistry and Physics, John Wiley \& Sons, Inc., New York, 1326p., 1998.

Simmons, A. J. and Gibson, J. K.: The ERA-40 Project Plan, ERA40 Project Report Series, 1, ECMWF, Reading, UK, 63p., 2000.

Stohl, A.: A one-year Lagrangian "climatology" of air streams in the northern hemisphere troposphere and lowermost stratosphere, J. Geophys. Res., 106, 7263-7279, 2001.

Stohl, A., Hittenberger, M., and Wotawa, G.: Validation of the Lagrangian particle dispersion model FLEXPART against large scale tracer experiment data, Atmos. Environ., 32, 4245-4264, 1998.

Stohl, A. and Trickl, T.: A textbook example of long-range transport: Simultaneous observation of ozone maxima of stratospheric and North American origin in the free troposphere over Europe, J. Geophys. Res., 104, 30 445-30 462, 1999.

Stohl, A. and Thomson, D. J.: A density correction for Lagrangian particle dispersion models, Boundary-Layer Meteorol., 90, 155167, 1999.

Stohl, A., Eckhardt, S., Forster, C., James, P., and Spichtinger, N.: On the pathways and timescales of intercontinental air pollution transport, J. Geophys. Res., 107, 4684, doi: 10.1029/2001JD001396, 2002a.

Stohl, A., Eckhardt, S., Forster, C., James, P., Spichtinger, N., and Seibert, P.: A replacement for simple back trajectory calculations in the interpretation of atmospheric trace substance measurements, Atmos. Environ., 36, 4635-4648, $2002 \mathrm{~b}$.

Stohl, A., Trainer, M., Ryerson, T., Holloway, J., and Parrish, D.: Export of $\mathrm{NO}_{\mathrm{y}}$ from the North American boundary layer during NARE 96 and NARE 97, J. Geophys. Res., 107, 4131, doi:10.1029/2001JD000519, 2002.

Stohl, A., Forster, C., Eckhardt, S., Spichtinger, N., Huntrieser, H., Heland, J., Schlager, H., Wilhelm, S., Arnold, F., and Cooper, O.: A backward modeling study of intercontinental pollution transport using aircraft measurements, J. Geophys. Res., 108, 4370, doi:10.1029/2002JD002862, 2003.

Wild, O. and Akimoto, H.: Intercontinental transport of ozone and its precursors in a three-dimensional global CTM, J. Geophys. Res., 106, 27 729-27 744, 2001. 